Christoph Martin Wieland - Sophie Brentano Briefe und Begegnungen 



\title{
Christoph Martin Wieland
}

\section{Sophie Brentano}

\author{
Briefe \\ und
}

Begegnungen

Herausgegeben von

Otto Drude

Akademie-Verlag Berlin

1989 
ISBN: 3-05-001040-1

Erschienen im Akademie-Verlag Berlin, Leipziger Str. 3-4, Berlin - DDR, 1086

(๑) VCH Verlagsgesellschaft, D - 6940 Weinheim

(Bundesrepublik Deutschland) 1989

Lizenznummer: $202 \cdot 100 / 223 / 89$

Printed in the German Democratic Republic

Gesamtherstellung: VEB Druckerei „G. W. Leibniz“,

Gräfenhainichen - DDR, $4450 \cdot 7324$

Schutzumschlag und Einbandgestaltung: Ralf Michaelis

LSV: 8023

Bestellnummer : 7551950 (9292)

02800 